\title{
通过《聊斋志异》分析中国封建社会的社会现实
}

\section{ANALYSIS OF SOCIETY CONDITIONS/REALITY DURING CHINESE FEUDAL ERA IN THE NOVEL LIAOZHAI ZHIYI}

\author{
Chen Chongjie $^{1}$; Yoan² ${ }^{2}$ Kelly ${ }^{3}$ \\ ${ }^{1}$ Chinese Department, Hainan Normal University \\ ${ }^{2,3}$ Chinese Department, Faculty of Language and Culture, Binus University \\ Jl. Kemanggisan Ilir III No.45, Kemanggisan/Palmerah, Jakarta Barat 11480 \\ cchen369@yahoo.com.cn
}

\section{内容提要}

《聊斋志异》是清代小说家蒲松龄创作的一部以志怪为主的文言短篇小说集, 它不是单纯的奇异 故事, 而是以奇异色彩叙写人生作品通过现实世界与虚幻世界来影射当时封建社会的社会现实。为了进 一步理解《聊斋志异》的现实意义, 笔者通过《聊斋志异》中的一些故事, 以叙述分析法从教育、政 治、爱情、经济以及伦理道德等方面分析作品反映出的社会现实。《聊斋志异》借狐鬼花妖之形, 写嬉 笑怒骂之情, 通过各种神鬼妖精的动人故事, 从教育、政治、爱情、经济以及伦理道德等方面反映了广 阔的现实生活，内容积极丰富：抨击科举制度的腐朽和弊端、暴露封建统治的黑暗和罪恶、歌颂青年男 女追求婚恋自由的行动、展示了女性在经济上的独立与社会地位的提高、总结了社会人生的经验教训。

关键词：聊离志异、封建社会、社会现实、蒲松龄、神鬼妖怪、中国

\begin{abstract}
Liaozhai Zhiyi is a compilation of short stories created by the Qing Dynasty novelist, $\mathrm{Pu}$ Songling. The main concept is not centered on regular ghost stories, but the author told a story on real life and the fantasy world by describing realities of society life in the feudal era. The author, through stories in Liaozhai Zhiyi, analyses social reality in their education, politics, love, economic and moral aspects. The author of Liaozhai Zhiyi uses of a lot of stories concerning fox spirits, ghosts, and other types of spirits in portraying his critics and anger towards incidents happening in feudal China. Analysis shows that Liaozhai Zhiyi broadly depicts social reality happening in feudal era in education, politics, love, economic and moral aspects. Liaozhai Zhiyi also criticizes the corrupt government official examination scheme, and the crime and decadence of the feudal government. In contrast, the stories also praised the freedom of young men and women seeking love in marriage, endorsing young men and women to reject arranged marriages, showing women in the economic independence and social advancement, and summed up the lessons of social life.
\end{abstract}

Keywords: Liaozhai Zhiyi, feudal era, social reality, Pu Songling, ghosts and spirits, China 


\section{前言}

鬼的观念产生于人类早期对灾异、疾病、死亡等无法理解现象的认识上, 他们认为有一种 神秘的力量在支配着人间的一切, 而这种力量又超越自然, 让人无法理解, 为了去理解它, 人 们就开始创造有关鬼的观念, 创造出各种各样的鬼现象和鬼故事, 这引起一些文人的兴趣, 记 录下来, 成为 “鬼笔记” 。有些文人记录鬼事时, 还进行了加工整理, 有的还进行了再创作, 就这样渐渐地产生了鬼小说。

明清时期, 由于封建政治严酷, 文人们很难秉笔直书, 批评时政, 抨击奸侫。一些人遂借 鬼谈人, 直抒胸臆, 又痛快又安全。

在以志怪传奇为特征的文言小说中, 最富有创造性、文学成就最高的是清初蒲松龄写的 《聊斋志异》。全书共有短篇小说 491 篇。题材非常广泛, 内容极其丰富。多数作品通过谈狐 说鬼的手法反映了 17 世纪中国的社会面貌, 对当时社会的腐败、黑暗进行了有力批判, 在一 定程度上揭露了社会矛盾, 表达了人民的愿望。但是, 其中还夹杂着一些封建伦理观念和因果 报应的宿命论思想。

《聊斋志异》借鬼谈人、充满奇异色彩, 引起了笔者更近一步研究的兴趣。笔者通过《聊 斋志异》当中的一些故事, 从教育、爱情、政治、经济, 以及社会伦理道德等方面分析作品反 映出的社会现实。

\section{内容}

\section{一、蒲松龄与《聊斋志异》的成书过程}

《聊斋志异》是一部著名文言短篇小说集。在《聊斋志异》的名字当中, “聊斋” 是清 代小说家蒲松龄的书屋名称，“志”是记述的意思，“异”指奇异的故事。

\section{（一）蒲松龄的生平}

蒲松龄（1640－1715），字留仙，别号柳泉，山东淄川（今淄博市淄川区）人。清顺治十 五年（1658），十九岁的蒲松龄参加科举考试，在县、府、道三次考试都考第一，录取蒲松龄 的是山东学政、大诗人施闰章。但接连四次乡试 (举人考试) 却名落孙山。追根究底, 并非是 他无才, 学识不够, 科举考试的八股文在形式上有严格要求, 但蒲松龄却写成了一篇既像小品 又像小说的文章, 不符合八股文的要求。虽然如此, 爱才如命的施闰章却欣赏蒲松龄栩栩如生 的小品文。

蒲松龄虽然得到施闰章的赞赏，其他考官却不会认可。他们都是用呆板的八股文做敲门砖 取得功名的, 只会写那样的文章, 也只欣赏那样的文章。因为施闰章的赏识, 也可以说是 “误 导”，蒲松龄在最初参加科举考试时就偏离了轨道。

大作家蒲松龄为 “举人” 功名, 用了不少于三十年的时间反复参加考试, 屡战屡败, 屡败 屡战。年过半百的蒲松龄被考试折磨得身心憔悴, 却不肯放弃对举人的追求, 直到七十二岁时 才援例补了一个岁贡生。 
蒲松龄二十五岁时，他跟哥哥们分家，家分得很不公平，对蒲松龄不利。为了养家糊口， 蒲松龄从此开始了长达四十五年的私塾教师生涯。私塾教师是得不到功名的读书人的出路。蒲 松龄在缙绅人家——毕家坐馆为生, 教富家子弟读书。他在毕家足足待了三十个年头, 七十岁 才撤帐归家终老。身份地位很低的农村私塾教师确实生活艰难。

14 至 19 世纪, 是中国封建社会衰落的明清时期。1661 年, 民族矛盾与阶级矛盾非常尖 锐, 被长期战争破坏的社会生产亟待恢复。在这种情况下, 老百姓的生活很困苦, 蒲松龄也不 例外。蒲松龄最愁的是如何不让催税的人登门。当时官吏为了催税, 搞所谓 “敲比” , 就是把 欠税的人拖到公堂上打板子, 有时甚至会把人活活打死。蒲松龄为了交税, 要卖掉缸底的存 粮, 卖掉妻子织的布, 甚至卖掉耕牛。蒲松龄一生很贫苦, 始终是劳苦大众中的一员。

\title{
（二）《聊斋志异》的成书过程
}

\begin{abstract}
“蒲松龄从小就喜欢天马行空的作品，酷爱小说。他青少年时代是明末清初，在那个混乱动荡改朝 换代的岁月里，人的生活困苦，种种社会现象引起了作家深沉的思考。蒲松龄大概在分家以后， 做私塾教师时，就开始写《聊离志异》。”
\end{abstract}

(百家讲坛栏目组，2007：521)

蒲松龄写《聊斋志异》时受到了朋友的反对。他的朋友张笃庆与孙䒹认为写志怪小说不利 于科举, 应该放弃创作, 但蒲松龄没有采纳朋友的劝告, 仍然写出了《聊斋志异》。虽然蒲松 龄写《聊斋志异》的事受到了朋友们的劝阻, 但他却受到了一位台阁大臣王士祯的赏识。这让 蒲松龄非常激动, 真诚地希望王士祯能给《聊斋志异》写序, 可王士祯最终没有给他写。

《聊斋志异》的故事其中有采自当时社会传闻; 也有就前人的记述加以改制、点染的, 如 《种梨》与原本于《搜神记》中的《种瓜》的基本情节相同; 还有完全或基本上有作者虚构的 狐鬼花妖故事，如《婴宁》、《黄英》、《公孙九娘》等。蒲松龄从小 “喜人谈鬼”，搜集很 多怪异故事, 又融进自己的生活经验和思想感情进行创作。在康熙十八年 (1679) 春, 他将已 经写成的篇章结集成册, 定名为《聊斋志异》。

科举的失意和生活的清苦, 使蒲松龄能够更多地接触劳动人民, 并对他们产生同情。蒲松 龄一辈子没当上官, 这反而使他得以专心于写作, 到 75 岁离开人世的时候（清康熙 54 年, 公 元 1715 年）给人们留下了一个内容丰富、情节感人的《聊斋志异》。

\section{二、《聊斋志异》的奇异世界}

从根本上说, 文学创造的反映对象是社会生活。社会生活是文学创造的反映对象, 也是文 学创造的唯一源泉, 无论作家在作品中写的是什么, 归根到底都根源于社会生活。作家总是生 活在一定的社会环境、一定的文化传统中, 他选择何种生活为创造的具体客体, 都必然受到社 会生活这个 “一般客体” 的规定和制约。而进入具体创造过程中, 创作主体的一切创造性活 动, 包括虚构、想像、情感投射、观念移注等, 都不可能离开具体客体进行纯粹任意的胡编乱 造和情感发泄。（童庆炳，2008：96，98）

蒲松龄写的《聊斋志异》也脱离不了社会生活。蒲松龄通过现实世界与虚幻世界来影射他 当时的社会生活。现实世界指人界; 虚幻世界指仙界、冥界和妖界。中国道家认为, 宇宙分为 三界: 上则仙, 中则人, 下则鬼。人行善积德可以成为神仙, 神仙贬谪到人间就成为了凡人, 
凡人作恶就成了鬼, 而鬼积德行善就可以复生为人。所以仙界是道家认为的最高的境界, 也是 中国老百姓民间传说的最高的境界。（英子，2005）

人、神、鬼三界在《聊斋志异》没有明显的界线, 人可以出入鬼神世界, 而鬼可以在人间 为非作多。这三界都被作者用作故事的框架而故事内容包含着社会现实的或作家个人心迹的景 象。

(一) 神仙世界

“在古代小说家笔下，仙界存在于天界，存在于海底龙宫，存在于深山洞府，是不老不死的乐园。 那里有奇树珍果，香花瑶草，美人仙乐，玉液琼浆，有永远的享乐和永恒的生命。到了《聊斋志 异》里，仙界除了天界、龙宫、深山洞府之外，还经常出现所谓“点化”的仙境，人不需要寻仙， 尘世就是乐土，仙乡就在现实中。”

(马瑞芳，2007: 3)

“聊斋遇仙题材的小说有一种“幻由人生”的哲学。“幻由人生”是整个聊斋小说的哲学理念。“幻由人 生”的意思是“幻境是由人在心里制造出来的”, “只要你对生活中的美好事物执着地追求，热切地盼 望，你所期望的一切就可以在你面前出现”。”

(马瑞芳，2007：101)

在聊斋仙界里, 没人催税, 没有贫困, 没有欺凌, 人们过着安乐、幸福的生活, 是一种 真、善、美的世界。《聊斋志异》的仙界代表了作者向往的理想生活，表达了下层贫苦大众的 美好愿望，而这个 “仙界”在当时社会中是不可能存在的，只能是作者的理想。

在《聊斋志异》当中, 以仙境为背景的故事, 有《正仙》等。《正仙》中, 正仙用他的法 术给高玉成展示出难以可信的美景：寒冬腊月的后院突然变得春天般温暖，异鸟成群，青鸾、 黄鹤、风凰、巨蝶。这些异鸟飞来飞去给灭仙和高玉成捧茶, 巨蝶变成了美丽的舞女, 跳起舞 来。这个像仙境般美丽的景象其实是虚幻的, 它不是现实景象, 而是人生所向往的美好地方。 人们希望能够在这样美好的地方生活, 他们不必担忧任何事情, 能安心地享受生活中的幸福。 可惜，这美好的地方在封建社会时期却是不可能存在的。

\section{（二）幽冥世界}

“前人认为，人死为鬼，鬼形成阴界。人死为鬼，灵魂归泰山，泰山神下边有若干管理机构。等到 佛教传入中国，佛教的地狱概念和中国传统鬼故事结合，阴世有了更完整的结构，有形形色色的 鬼。”

(马瑞芳，2007: 4 )

阴世最为明显的代表是地狱，地狱被一些人认为是人死后灵魂回到的地方。在《聊斋志 异》里，阴世不只是指地狱，灵魂、女鬼、恶鬼的形象也形成了神秘的阴世。

聊斋写的是生活中并不存在的鬼，而且用鬼魂影射社会，有深刻的社会背景和现实意义。 在《席方平》里, 席方平为受凌辱的父亲入冥府申冤, 层层上告。没想到, 地狱的城隍、郡 司、冥王各级衙门都已被羊某贿赂了。不但不能为父亲申冤, 自己也屡受冥府酷刑。 
地狱是对人生前行为总清算、对恶行恶德总惩罚的场所, 也可以说是阴间的监狱和刑场, 是公正无私、主持公道的地方, 在蒲松龄笔下却变成一个混乱的地方, 黑暗更甚于阳世。冥 王、城隍向来被传为铁面无私的法官, 在《席方平》中竟成了贪赃枉法的赃官酷吏。这无声胜 有声地暗示出当时阳世政府比阴世政府的腐败更严重, 各级部门的酷吏官官相卫, 公正的生活 很难来实现。《席方平》批判了当时封建社会的政府的腐败, 对冥间的揭露其实就是对现实社 会的揭露。

\section{（三）妖精世界}

“凡是人类之外的动物、植物、器物变化成人，或者虽然没变化成人却能像人一样说话，跟人交 往，就叫妖精。《聊离志异》写了很多自然界精灵：天上的小鸟、水中的白鯺豚、地上的鲜花、 深山的狼虫狐豹，甚至书里的蚌虫、田野的老鼠，都扮演重要的角色。聊斋的精灵或妖精不是吃 唐僧肉的妖精，而是帮助人、爱护人的护法者，充满情与义的妖精。”

(马瑞芳，2007:6，91，93)

聊斋写精灵是为了阐明很深的社会伦理。《阿绣》中的狐女为赢得刘子固的爱情, 幻化成 刘子固所爱的阿绣, 在美与爱的竞争中却被刘子固对阿绣的痴情感动, 意识到阿绣的真和美, 便转而促成刘子固与阿绣结合, 让所爱者爱其所爱。蒲松龄通过《阿绣》歌颂了高尚的哲学, 也是美的哲学。狐女以德报怨, 替刘子固找到真阿绣, 不是爱情的第三者, 而是真爱的缔造 者。狐女在追求外表美的同时，也获得了内心美。

《聊斋志异》里绝大部分篇章叙写的都是神仙狐鬼精鬼未故事，具有超现实的虚幻性、奇异 性, 往往添加些虚幻之笔, 在现实人生的图画中涂抹上奇异的色彩。狐鬼花妖故事不完全是在 原来迷信意义上，而是弃其内质，存其形态，从而摆脱了神道意识的拘束。神仙、狐、鬼、花 妖, 都是出自他个人的心灵的创造, 个中有所寄托、寓意。他以假虚拟狐鬼花妖故事抒写人生 苦乐，抒发情怀，及寄托忧愤。

\section{三、《聊斋志异》中反映出的社会现实}

社会生活作为文学创造的反映对象是特殊的, 其特殊性主要是 : 第一, 是整体性的社会 生活。文学反映的生活不局限于某一方面或层次, 而是多方面生活的交融、渗透, 是现象与本 质、具体与一般相统一的社会生活。第二, 是具有审美价值的社会生活。所谓具有审美价值的 生活, 不仅包括本身直接具有美的属性的生活, 也包括那些本身不直接具有美的属性, 甚至是 丑的, 但经过审美的提炼和转化之后, 具有审美价值的生活。第三, 是作家体验过的社会生 活。就是说, 只有作家体验过的生活, 才能成为文学创造的实际客体。这种体验是审美体验, 主要是情感体验。所以, 文学创造的实际对象是审美化、情感化了的生活。（童庆炳, 2008 ：96）《聊斋志异》反映出人生中各种各样的生活方面, 如爱情、教育、经济等方面, 而它里面的每个故事又不只是单纯地反映出一种生活方面而已。一个故事会涉及到其他的生活 方面。下面是对《聊斋志异》中的一些比较突出的故事的分析。

\section{（一）教育方面}

科举考试历来都是朝廷选拔人才的重要方式，也是文人走上政治仕途的重要途径。随着历 史发展, 到了明清时期时, 特别是清朝, 科举制度被少数腐败官僚垄断。他们徇私舞弊。这导 致了一些有才华的文人得不到功名。 
《叶生》里, 有个文章诗词都写得绝好的读书人叶生, 却屡试不中。故事结尾, 叶生终于 考中举人, 此时自己却发现早已经过世了。《叶生》的故事是取材于蒲松龄的个人悲剧, 描写 了科举时代才华出众而遭遇悲惨的读书人, 抒写了科举时代读书人为科举制度所害的苦痛, 表 达了作者怀才不遇的愤满。作品批判了科举制度的不公平。叶生怀才, 却一辈子得不到功名, 连人都已经变成鬼魂, 他还是一直追求功名, 不放弃他的意愿。蒲松龄通过叶生的形象寄托了 万千不得志的读书人对科举考试的期望。

《考弊司》里有个管理着书生的考弊司司主, 他有个特殊规定, 就是凡初次来谒见他的秀 才, 都要割下一块腿肉。如果贿赂些钱, 就不必要受罚了。阴界本来是个能够争取公正的地 方, 在《考弊司》里的阴间里却发生了舞弊。《考弊司》反映了当时科举制度的欺压与弊端, 揭示了当时封建统治考试中的种种腐败和毛病，这是多么黑暗的考场。

《于去恶》写陶圣俞赶赴乡试时, 遇到要赴试的冥中之鬼于去恶。在冥间士子入闱考试的 前一天得检查试官。可这次考试, 文昌帝君奉命外出, 于是检查试官之事没人去管, 试官中都 是不学无术和爱钱如命的一类人。试后于去恶虽然自负, 但终于落第。陶生在阳间也是落第。 直到科场舞弊案发之后, 陶生才考中。通过《于去恶》故事, 蒲松龄讽刺封建时代科举考试的 黑暗和种种弊端。无论在阳间还是在阴间的科举考试都是一样腐烂, 发生了许多不公平的事 件。对冥间的暴露其实就是对现实社会的暴露。考官都是爱钱的, 不录取有才华的书生, 却录 取能贿赂而无才华的书生。此外还有涉及到教育方面的故事, 如《贾奉雉》、 《王子安》、

《叶生》等故事。聊斋志异从科举考试的方方面面, 通过鬼怪故事揭露了给人造成危害的腐 败、落后的科举制度, 描绘出一个充满弊端的黑暗考场。贪欲的考官都欺压着文人, 死板的八 股文限制文人发挥自己的才能。这导致有才华的文人屡次考不中。

\section{（二）爱情方面}

爱情是美好的; 爱情是幸福的; 爱情也是痛苦的, 古往今来爱情是人们永恒的话题。 斋》中通过的鬼神形象，展现出各种可悲、可叹、可歌、可泣的爱情。

《连城》故事里讲述了连城的父亲史孝廉想挑女婿。连城看上了穷士乔生, 但史孝廉嫌乔 生穷, 想挑有钱人做女婿。连城被父亲逼迫与王生订婚, 可连城生生死死都要跟乔生在一起。 不久, 连城竟死了。乔生也悲痛过度而死。在阴间两人重逢。乔生在朋友的帮助下和连城双双 还魂。哪知王生贿赂贪官, 把复生的连城判给了他家。连城在王家不吃不喝, 并要上吊, 王生 没有办法, 只好放连城回家。乔生和连城永远在一起。《连城》表现了男女主人公在争取爱情 的过程中, 同封建礼教和世俗观念的曲折斗争。封建社会时期女人没有权力来选择自己理想的 对象, 婚姻是由父母来决定的, 男女要跟自己所爱的人在一起是很难实现的事情, 更何况男女 两个人的身份与地位不一样。在这个爱情故事里, 以封建家长、官府为一边, 以真心相爱的青 年男女为另一边, 在金钱不能诱、威武不能屈、生死不能隔的恋爱面前, 父母之命、金钱、官 府都被打败了。

孙子楚是《阿宝》的男主人公, 一只手长了六个指头。阿宝是美丽的富家少女, 家里给她 选女婿。孙子楚就向阿宝求婚, 阿宝却开玩笑叫他把第六指砍断。孙子楚果然那样做了。他痴 情得连魂魄都离开身体, 跟随着阿宝。被感动的阿宝同意嫁给他。过了三年, 子楚病死。阿宝 非常难过，自尽上吊。这感天动地的痴情打动了阎王，放他们夫妇同回人间，成就了 “千古一 对情痴”。这个故事写的是痴情, 全篇笔笔写痴, 字字关情, 主要围绕孙子楚的 “痴”、 “情” 做文章。在当时现实社会, 在男女之间只要有 “真心”、“至情” , 就可以冲破一切阻 力, 终成眷属, 实现婚姻理想。这种爱情观, 突破了封建主义的束缚。 
《画皮》写妻子陈氏为了救王生, 忍受着极大羞辱把乞正吐出的鼻涕粘痰吞下去。没想 到, 她吞下去的鼻涕粘痰竟能救活王生。《画皮》描绘了一个对丈夫很忠贞及热爱的妻子形 象, 表达了对丈夫纯贞的爱情。为了救活这已经背叛了自己的好色丈夫, 妻子还是愿意去做任 何能做的事情, 连差辱自己的事她都干了。事实上, 很难找到像陈氏那样贤惠、忠实的妻子, 很少人能做到像陈氏一样所做的事情, 纯贞地、执着地爱一个人并没有那么简单的。

此外, 涉及到爱情方面的还有《瑞云》、《紧宁》、《青风》等故事。

通过多样奇妙的故事, 《聊斋志异》展示出很多年轻男女怎样去跟不合情合理的封建婚姻 制度与封建礼教斗争的故事, 怎样去争取自己的自由和幸福, 如《连城》。有的通过 “痴情” 的人物形象表达了人们热烈的爱情。为了他们具有的 “爱情” , 他们去反对束缚着他们的世俗 观念和封建礼教。此外，有的故事还赞扬了贤妻对丈夫的忠贞之心与执着的爱。

\section{（三）政治方面}

政府该爱护人民，给人民一个安宁的生活，可在落后的封建时期，很多官僚贪污、为私情 而欺压了无幸的人民。这造成了混乱的境况。

《席方平》里, 先死的羊某害死了席方平的父亲。席方平为父亲申冤, 魂赴冥府, 层层上 告, 可城隍、郡司都已受羊某的贿赂, 非但不能为父亲申冤, 自己也倍受酷刑。他又向阎王控 告城隍、郡司, 不料阎王没有给他做主, 却惩罚他。席方平继续告状, 终于告到二郎神那儿, 从阎王到鬼卒都被二郎神严惩, 让席方平和父亲复活。席方平在阴司的遭遇, 实际上是当时人 间官吏与人民的关系的真实写照。《席方平》实际是对封建社会人间酷吏官官相护、残害人民 的控诉。《席方平》描绘了当时有那么腐败的政府系统, 那么多赃官酷吏因贪钱而虐待了无幸 贫苦的平民，平民很难得到公正与权力。

《促织》讲述了有个爱斗蟋蟀的皇帝, 为了满足自己的爱好, 不断地让百姓进贡蟋蟀。一 些官员为了讨好上司, 强迫每家每户按人口派蟋蟀。往往为了一只蟋蟀, 闹得家破人亡。《促 织》批判了当时社会的腐败和黑暗, 影射了封建统治的残害人民的罪行, 以及生活在那个时代 的百姓疾苦。为了满足统治者的欲望, 百姓都牺牲了他们宝贵的生命, 可在统治者的眼中, 它 却毫无意义、毫无价值。

《梦狼》中, 白翁梦见他来到做县令的白甲的官署。他进去一看, 堂上堂下都是狼, 而 阶前白骨如山。忽然来了两个金甲猛士捉住白甲，白甲扑地化成虎，猛士把白甲的门牙敲了。 白翁醒了后, 急忙派小儿子带上他的告诫信去白甲那儿看看。没想到, 小儿子一到那儿, 看到 白甲因骑马已经摔掉了门牙。蒲松龄把当时的官吏都比喻成虎狼。虎狼是凶猛吃人的动物, 官吏就像虎狼那样凶猛, 残酷地虐待老百姓, 使老百姓受苦, 在他们的酷刑下, 连人命都没 了。这些贪赃纳贿的官吏确实还比虎狼更厉害。通过《梦狼》, 蒲松龄想警告那些贪赃枉法的 官吏。故事里, 白甲终于得到报应。《梦狼》给人们的启示是恶行肯定会有恶报, 希望官吏们 会爱护老百姓。

此外，涉及到政治方面的还有《梅女》、《罗刹海市》、《公孙九娘》等故事。

《聊斋志异》从政治方面来看，通过鬼怪故事抒发了人民对当时政府的不满。官吏酷虐地 残害老百姓, 而老百姓却无能力或权力去复仇。这些人民的仇恨, 在《聊斋志异》里通过幻想 的形式都得到了申诉。《席方平》、《梅女》等故事描绘了被虐待的人民如何拼命地争取公 正, 赞扬了那些被压迫的人民反抗斗争的精神, 展示出 “正义必胜” 的坚强信念。 


\section{（四）经济方面}

古代, 男主外, 女主内。男生在外挣钱来养活家庭, 而女生在家作家务, 抚育孩子。可, 在《聊斋志异》中, 却出现了很有经济头脑的女强人。

《小二》写 “绝慧美”的女子赵小二，她为人灵巧，经营才能超过男人。她开个琉璃厂， 生产的灯样子新颖, 其他工厂都比不了。几年功夫, 她就变成最富有的人了。小二对工人管理 很严格, 工人没有一个吃闲饭的。努力的工人受到奖励, 偷懒的工人罚趾。《小二》展示了在 经济发展中女性的独力与地位的提高。小二是个女经营者, 她善于管理工人。小二懂市场, 她 知道怎样满足顾客的要求、怎样去掌握市场。女生不只是呆在家里、做家务而已, 依靠别人生 活，而自己能独立，去掌握自己的命运。

《黄英》写嗜菊如命的马子才邀请刚遇到的陶家姐弟住在他家南院。陶三郎和黄英是菊 仙, 他们把卖花当成事业做。不久, 马子才的妻子病死, 娶黄英为妻。几个月后, 马家的东西 都是从陶家拿来, 马子才耻以妻富, 认为黄英破坏了他的清风高名。黄英以她的经营能力养活 了家庭, 马子才不但不以她为荣, 反而觉得黄英伤害了男子汉大丈夫的自尊心。故事表达出当 时的传统男性观的观念。在封建社会中，女性没有社会生存能力，一般靠丈夫生活。

《细柳》里叙述了细柳是个相夫教子、勤俭持家的好妻子。细柳不喜欢做家庭的事情, 她 却接管丈夫经营的家业田产, 并处理得很好。细柳把家里的事务都管得井井有条。古代, 男主 外, 女主内。男人在外为官为商为陇耕, 而女子在家就是裁剪做饭教育孩子了。细柳不但管好 家里, 连丈夫的家业也被她管理得很好。细柳已给女人做出了榜样, 无论是在事业上还是在家 庭上，她都是一个成功的女人。

《聊斋志异》从经济方面来看, 蒲松龄通过聊斋女性展示了女性在经济上的独立与地位 的提高。当时女人都没有社会生存能力和地位, 只能靠丈夫生活。可在《聊斋志异》的一些故 事，女人却能够自己独立，他们不再是家庭负担，而是能养活家庭的富有头脑的经营者。

\section{（五）社会伦理道德方面}

道德是人们共同生活及其行为的准则和规范。道德通过人们的自律或通过一定的與论对社 会生活起约束作用。《聊斋志异》通过神鬼妖精的形象告诉了人们怎么去做人, 给了我们很多 的人生启示。

《画皮》里, 王生清早走路, 遇到一个漂亮姑娘。王生心里产生邪念, 把美女带回家, 跟 她同居。妻子劝他将这女子打发走, 可王生不听。没想到, 美女竟是一个披上人皮的恶鬼。最 终, 恶鬼掏取了王生的心, 走了。《画皮》蕴含着具有广泛警世作用的生活哲理。蒲松龄用这 个怪异故事来劝谕世人, 人必须心地正直, 不要走邪门歪道。不要像王生那样, 因心底产生邪 念，而最后失去了宝贵的生命。心底有邪念的或者做坏事的人最终肯定会受到果报。世界上， 有很多像《画皮》里的 “恶鬼”，披上好人的外表来欺骗、陷害人们。头发一样黑, 人心谁可 知，因此，世界上善良、幼稚的、头脑简单的人要提高警惕，不要上当受骗。

《劳山道士》写了王生从小就美慕道家的法术, 听说劳山上有很多仙人, 就去访求。王生 就被一个道士收下来，可道士不教给他法术，让他天天砍柴。王生吃不了苦，很想回家，可一 看到道士的法术, 他又忍耐下来了。终于苦不可忍, 跟道士要求回家, 且要求道士教他一个小 法术。道士就教他穿墙的法术。当时试验很灵, 没想到, 回到家给妻子表演时却触壁跌倒。这 
篇故事至今有启发意义: 人想取得成就, 必须付出艰苦劳动, 就像小说写的, 老老实实砍柴, 从最基础工作做起, 想取巧, 走捷径, 没有不碰壁的。做任何事情, 我们都要有毅力, 刻苦努 力地追求它, 不要容易放弃。想要得到好成就, 就要尽力去争取它。

《聂小倩》说到深夜有个美丽女子聂小倩主动送上门, 说要跟正直的书生宁采臣亲热。宁 采臣断然拒绝。美女又拿来一锭黄金, 宁采臣却把黄金丢到院子里。对美人和黄金却不动心, 于是他才能免于灾难。聂小倩这两手实际上很有现实性、普遍性, 古往今来男人大多数都很难 度过两个关, 这就是金钱关和美人关。但是在《聂小倩》里的宁采臣却给社会做出了榜样, 没 被美人引诱, 也没被金钱吸引。通过《聂小倩》蒲松龄表达了他对人们的希望, 希望在道德败 坏的封建时代, 人们都能像宁采臣一样拥有着一颗纯正、正直的心肠。

此外, 涉及到伦理道德方面的还有《翩翩》、《婴宁》、《种梨》等故事。

《聊斋志异》充满道德训诫意义, 对人进行教育和劝诫: 教育人要心底善良、诚实、乐于 助人、吃苦耐劳、知过能改等等。它总结了社会人生的经验教训, 也热情地歌颂了普通人的种 种美德和情操。

\section{结语}

《聊斋志异》的故事大多数是现实主义和浪漫主义结合的作品, 通过神鬼花妖精怪形象反 映了广阔的现实生活, 内容非常丰富: 暴露封建社会政治的黑暗、腐败; 抨击统治阶级的罪 恶; 歌颂被压迫人民反抗斗争精神; 揭露科举制度的弊端和罪恶; 揭露封建婚姻制度的不合 理; 赞美超越生死的爱情力量; 歌颂青年男女反对封建压迫、挣脱封建礼教束缚、争取婚姻自 由等要求和行动; 女性的独立与社会地位的提高; 总结了社会人生的经验教训。

聊斋三界之间没有界限，不管在教育、爱情、政治或其他方面的故事，三界都穿插变换。 人间解决不了的问题, 就到阴间来解决, 阴间解决不了, 就到仙界去解决。在三界之间, 仙界 是最高的境界, 人们最向往的境界。聊斋三界故事在意蕴上有所分工: 冥界题材主要负载对社 会的批判; 妖界故事主要负载对芸芸众生的广泛观察和思考; 仙界故事主要负载作者真善美的 理想。蒲松龄期望读者不是信以为真, 而是能领会寄寓的意蕴。

《聊斋志异》能广泛地流传到现在, 是因为社会的黑暗及人们对美好的追求还依然存在, 它不仅有反映社会现实生活的作用, 而且作为人们行为的指南针, 指导着人们努力去追求 “真 善美”这一人生的最完美境界。

\section{参考文献}

百家讲坛栏目组. (2007). 百家讲坛精品集[M]. 上海：上海文艺出版社

冯胜利、冯禹. (2006). 用中文谈中国[M]. 北京：北京语言大学出版社

方迎九、赵锦丽等. (2003). 中国文学名著快读[M]. 四川: 四川文艺出版社

金素芳、徐国普. (2009). 仰斋志异[M]. 杭州: 浙江少年儿童出版社 
李家巍、曲德来. (2006). 中国文化十万个为什么[M]. 北京：辽海出版社

刘泽彭. (2007). 中国历史常识[M]．北京：高等教育出版社

刘晓. (2009). 论《聊斋志异》中的择偶标准及其审美情趣[J]. 西南农业大学学报（社会科 学版）, 7. (2) : 130-133.

流穿蜂. (2001年1月).蒲松龄[Z]・2010年1月4日参考于

http://baike. baidu. com/view/7721. htm\#8

马书田. (2008). 中国鬼神[M]. 北京：团结出版社

马瑞芳. (2007). 马瑞芳说聊斋[M]. 北京：作家出版社

南帆、刘小新、练暑生. (2008). 文学理论基础[M]. 北京：北京大学出版社

蒲松龄. (2007) ). 聊斋志异：连环画珍藏版[M]．天津：天津人民美术出版社

孙桂文、高延晶. (2003). 中国通史[M]. 河南：海燕出版社

童庆炳.（2008）。文学理论教程教学参考书（修订二版） [M]. 北京：高等教育出版社

英子. (2005年10月).马瑞芳说聊斋之《仙境》[Z]. 2010年1月4日参考于

http://www. cctv. com/program/bjjt/20051019/101409. shtm1. 2005-10-19.

袁行霈. (2004). 中国文学史[M]．北京：高等教育出版社

袁行䨟. (2002). 中国文学概论[M]. 北京：高等教育出版社

第七章《聊斋志异》[Z]. 2010年7月18日参考于

http://iclass. nbtvu. net. cn/kecheng/072157/4title4200499131247/z4. htm

Nio, Joe Lan. (2004). Sastra Cina Sepintas Lalu. Jakarta: PT. Bhuana Ilmu Populer 